\title{
Influence of geometric variables on spur gear volume
}

\author{
Edmund S. Maputi ${ }^{1, *}$ and Rajesh Arora ${ }^{2}$ \\ ${ }^{1}$ Department of Industrial and Manufacturing Engineering, Harare Institute of Technology, Belvedere, Harare, Zimbabwe \\ 2 Department of Mechanical Engineering, Amity University Haryana, Gurgaon 122413, India
}

Received: 31 December 2019 / Accepted: 11 May 2020

\begin{abstract}
Gear system optimization is currently topical amongst researchers. To this end, problem formulation is key and therefore knowledge of parameter influence and variation behaviour is indispensable. In this research work, four gear volume models were investigated for volume minimization while considering six variables viz. face width, module, pinion tooth, hardness, and pinion and gear shaft diameters. Three algorithms viz. teaching learning-based optimization (TLBO), particle swarm optimization (PSO) and firefly algorithm (FA) are employed to obtain the optimal volume and design parameter variation study. The convergence rate of each algorithm for each gear model is contrasted against other algorithms applied in the study. Experimental runs have also been conducted to determine standard deviation and mean values. Variation studies on the volume objective reflect relevant observations noted for parameter setting and optimization. The results obtained can assist the designer in setting designer preferences with minimal resources expended thereby improving the problem-solving exercise.
\end{abstract}

Keywords: gear / optimal design / design preferences / optimization

\section{Introduction}

Gear systems are the fulcrum of defined motion in machinery, especially where a specific rotational speed, torque and/or power output is required.Volume and/or efficiency remain the most common objectives in current literature [1,2]. Furthermore, these have been investigated while applying design variables such as viz. gear teeth number, face width, module, addendum modification and profile shift factors. Most researchers do not report on the criteria applied for selection of variables which is key for pre and post optimality analysis.

The application of optimization methods in the study of gear systems is common in literature. Methods such as genetic algorithm (GA), firefly algorithm (FA), grey wolf optimization (GWO), simulated annealing (SA), teaching learning-based optimization (TLBO), particle swarm optimization (PSO), etc. exist in gear literature [3]. In terms of gear types, literature reflects that more research work has been done on spur and helical gears as compared to bevel and worm gears [4,5]. This could be attributed to the wide spread application and common use of parallel axis gears such as helical and spur gears. Single objective formulations were investigated by Tamboli and Rai et al. $[6,7]$ focusing on volume minimization while applying PSO,

\footnotetext{
* e-mail: esmaputi@gmail.com
}

and real coded genetic algorithm (RGA) respectively. Increasingly more multi-objective optimization studies on volume, power output, efficiency have been recorded in literature [8].

In order to understand the optimization process and improve problem formulations, researchers have also investigated the influence of variables on various objective functions. Through experimentation and application of computational fluid dynamics (CFD), the influence of lubrication properties on gear design parameters is determined [9]. Investigations have not been limited to lubrication parameters only but design and geometric parameters have also been studied [10]. Focusing on high efficiency gears, researchers have introduced an original method utilizing contact ratio to determine efficiency of gears [11]. In some cases, 'a priori' knowledge of objective weights elicits the use of methods such as the weighted coefficients method on multiple objective optimization [3].

Literature reviewed reflects a keen interest in understanding potential relationships between design variables and objectives. The literature reviewed has shown absence of parameter study on volume models except those investigated by Wang et al. [12]. The influence of design variables with respect to the volume of gear has not investigated. This reflects a research gap on gear parameter influence with regard to volume optimization. A number of researchers have carried out optimization studies by considering various systems using genetic algorithm, 


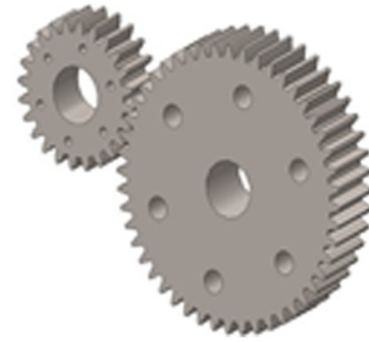

a)

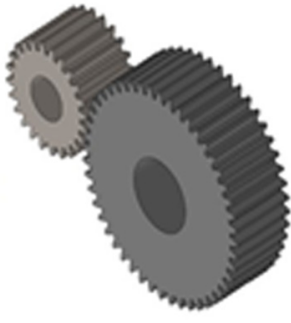

b)

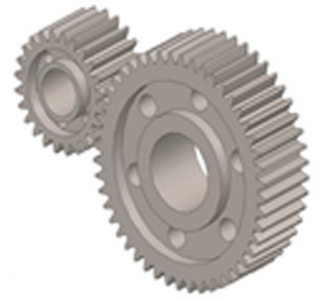

a)

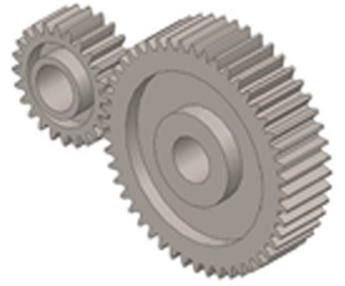

b)
Fig. 2. (a) Hub-hole profile, (b) Hub profile.

Fig. 1. (a) Solid-hole profile, (b) Solid profile.

NSGA-II and other evolutionary algorithm techniques [26-35]. It is the view of the researchers that understanding design parameters in detail with respect to objectives can significantly improve problem formulation, selection of variables and the ultimate solution obtained.

This research work investigates volume minimization of a spur gear design based on four gear structures. Six design variables viz. module $(m)$, face-width $(b)$, number of pinion teeth $\left(z_{1}\right)$, pinion shaft diameter $\left(d_{1}\right)$, gear shaft diameter $\left(d_{2}\right)$ and gear tooth hardness $(H)$ have been considered. Furthermore, three optimization methods viz. TLBO, FA and PSO have been applied for optimal value search and validation. Experimental runs to determine standard deviation, mean and optimal value for each algorithm have also been conducted and reported. A variation of volume against each design variable under investigation is also carried out reflecting parameter influence.

The current research work is structured as follows, Section 2 introduces the four gear structures and description of system under investigation. Section 3 discusses optimization techniques and focuses primarily on the TLBO, FA and PSO algorithms. Section 4 introduces the mathematical model to be applied for each gear structure. The results are displayed and interpreted in Section 5. Variation study is performed in Section 6 for all design variables.

\section{Volume structures and system description}

Gear structures vary in form and configuration, and in this research work, the authors focused on four gear structures. The gear models being structurally solid gears with features such as weight reduction holes and hubs to strengthen gear tooth section are also included. A solid-hole profile is shown in Figure 1a, which is basically a solid-profile as shown in Figure $1 \mathrm{~b}$ but with weight reduction hole features.

A hub-hole profile is shown in Figure 2a which has both weight reduction holes and gear hub features.Besides improvement of the strength of gear teeth, hubs contribute in overall volume and weight reduction. The fourth gear structure is a hub-profile shown in Figure 2b.

\subsection{System description}

In the design of gears, the resultant design is realistic or practical when design limitations are set as constraints.
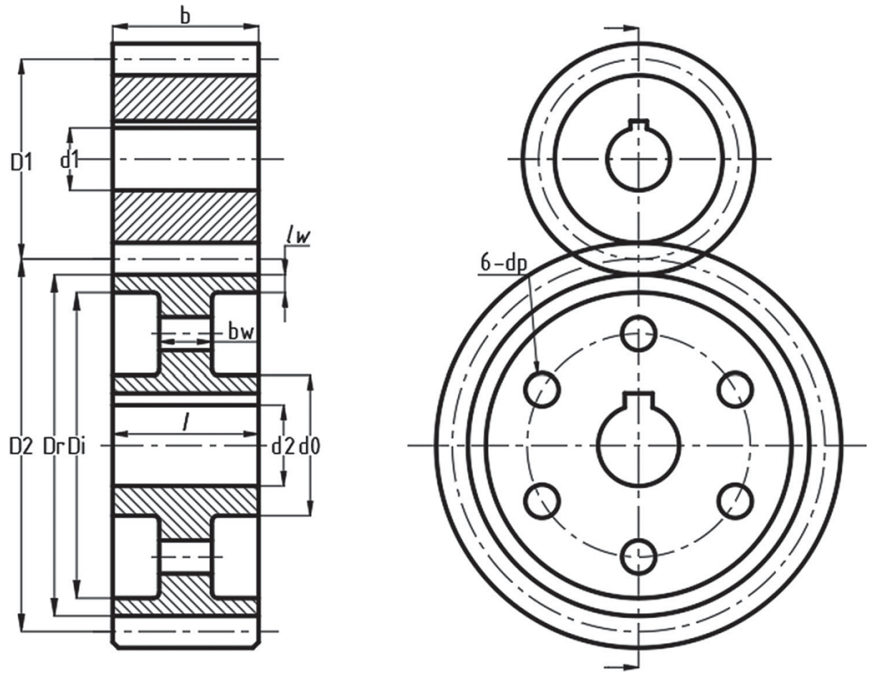

Fig. 3. Gear parameters [15].

Constraints with respect to physical structures will vary being classified as geometric, design and control parameter constraints [13]. Geometric constraints evaluate parameters so that the physical dimensions and boundaries of components are maintained thereby avoiding interference in assembly. Design constraints check for the suitability of the design parameter set against known design standards in gear design. On the other hand, control parameter constraints ensure the basic rules of parameter relations remain in force.

Failure in gear operation occurs mainly due to contact/ surface and bending stress. The balance in favor of either stress factor depends on the application, selection and computation of safety factors. In this research work, stress limitation and design factors utilized are according to ISO 6336- 1 to ISO $6336-3$ [14].

In the current research work, a single-stage spur gearbox consisting of two gears (pinion and gear) is investigated. The sectional view of the four gear models is shown in the two-section diagram in Figure 3, as a parallel axis gear arrangement. For each gear model considered, both gears are structurally modelled as solid discs with a shaft hole in the middle. Additionally, hub and hole features integral on three volume structures are also shown. The input design parameters are shown in Table 1.

\section{Optimization techniques}

Optimization algorithms manage the search process within a solution space while seeking for optimal results.However, 
Table 1. Input parameters.

\begin{tabular}{lll}
\hline Description & Value & Unit \\
\hline Power input & 50 & $\mathrm{~kW}$ \\
Input speed & 1930 & $\mathrm{rpm}$ \\
Output speed & 480 & $\mathrm{rpm}$ \\
Pressure angle & 22 & degrees \\
Allowable bending stress & 200 & $\mathrm{~N} / \mathrm{mm}^{2}$ \\
Allowable contact stress & 400 & $\mathrm{~N} / \mathrm{mm}^{2}$ \\
\hline
\end{tabular}

a solution is only as good as the problem definition. As such ineffective problem formulation results in a premature convergence and suboptimal solutions. In such a case, convergence to a solution could be sufficiently rapid but not optimal. The optimization process for the function $f(x)$ may be defined by equation (1).

Minimize

$$
\begin{aligned}
& F(x)=\left[x_{1}, x_{k}, \ldots, x_{k+1}\right] \\
& g_{i}(x) \leq 0 \\
& i=1,2, \ldots, n ; h_{j}(x)=0 ; j=1,2, \ldots, p
\end{aligned}
$$

where $k$, represents the set of variables considered in the problem, $i$, represents the set inequality constraints, $p$, represents the set of equality constraints, $g$, the constraint functions, $h$, equality functions and, j, the set of equality constraints.

The third observation recognizes the presence of an analysis stage in both methods, which becomes the starting point for successive iterations. The design problem formulation as shown in equation (1) aids parameter adjustments between iterations. This is important since design, is a process that links design parameters and functional requirements. According to Messac [16] design seeks to map conceptual thinking, formulation of objectives, and the optimization process.

In engineering design, mathematical formulations are dependent on various design standards and material properties, which impose a myriad of influence on the design objective/s [17]. The independence and adequacy of these variables is also an important attribute for consideration when formulating the optimization problem. Optimization in engineering design processes considers various criteria such as fatigue, bending strength, interference, etc. The consideration of such criteria occasionally results in complex problem formulations, which could be of a non-linear nature. Furthermore, the topology of the search space can be such that numerous local optima exist [18], while the designer is desirous of the global optima. In such cases, classical techniques fall short, and tend to descend in local optima.

Classical optimization techniques such as simplex, geometric, dynamic programming are problem, variable and constraint type specific [19]. Due to this specificity, classical algorithms are not universal in application.

Research in artificial intelligence, has led to more advanced optimization techniques. Unlike classical techniques, these new algorithms are universal in application as evidenced by their application in literature. Advanced optimization techniques are robust and handle dynamism in the search environment better than classical techniques. Another significant advantage is their ability to hybridize and to search for unknown solutions. Due to these advantages' researchers are employing advanced/evolutionary techniques, which are resultantly universal and more effective in application [20]. Such techniques include Artificial Bee Colony (ABC), Bacteria Foraging Optimization (BFO), Particle Swarm Optimization (PSO) and Shuffled Frog Leaping (SFL).

\subsection{Teaching learning}

The TLBO algorithm emanates from relative behaviour of participants in a classroom setting. It explores the teacherstudent and student-student relationship in a classroom or learning environment. The former is the teacher stage/ phase and the latter refers to the learning stage/phase. In the teacher stage, students interact with the teacher in order to improve their knowledge. Naturally, students in a class pursue a particular curriculum composed of subjects / courses, with an evaluation of marks obtained at the end of the course. In other words, a class of students represent the population, the subjects offered represent the variables, while the result from evaluation is the fitness function. The teacher result is as an ideal solution in the search space (population). Considering an optimization problem, the variables herein mentioned are the design parameters and the objective function is analogous to the best solution. The optimization process of this algorithm is composed of two phases known as the teacher stage/phase and the learner stage/phase as shown in Figure 4. Reflect a general increase in the individual results of the students. Ideally, the goal is to approach the best result throughout the population. In TLBO, the best result is the teacher. This is due naturally, since the teacher is the more experienced or advanced learner in the class. In the teacher phase, the students (learners) acquire knowledge from the teacher. The teacher in this stage seeks to upgrade the knowledge level of the class.

In optimization problems, algorithms perform numerous iterations as defined by the user. In TLBO, any iteration $i$, will be defined by the number of subjects and learners respectively denoting variables and population. For each subject the corresponding difference in the mean result and that of the teacher is computable. This is the product of a random value and the difference of the best value and the product variable mean and teaching factor. The teaching factor ( $\mathrm{TF}$ ) is a value, which is determined randomly. Experimental runs on numerous benchmark functions have shown that when TF is either 1 or 2 , better solutions emerge [6].

For the sake of simplicity, the value of TF is set as either 1 or 2 depending on the equation. As shown in Figure 3, the initialization process gives way to the teacher section of the algorithm. The ranking of obtained solutions against the mean value by superiority is the secondary step.

The calculated difference mean sums to the present value for updating. The learner phase is the secondary 


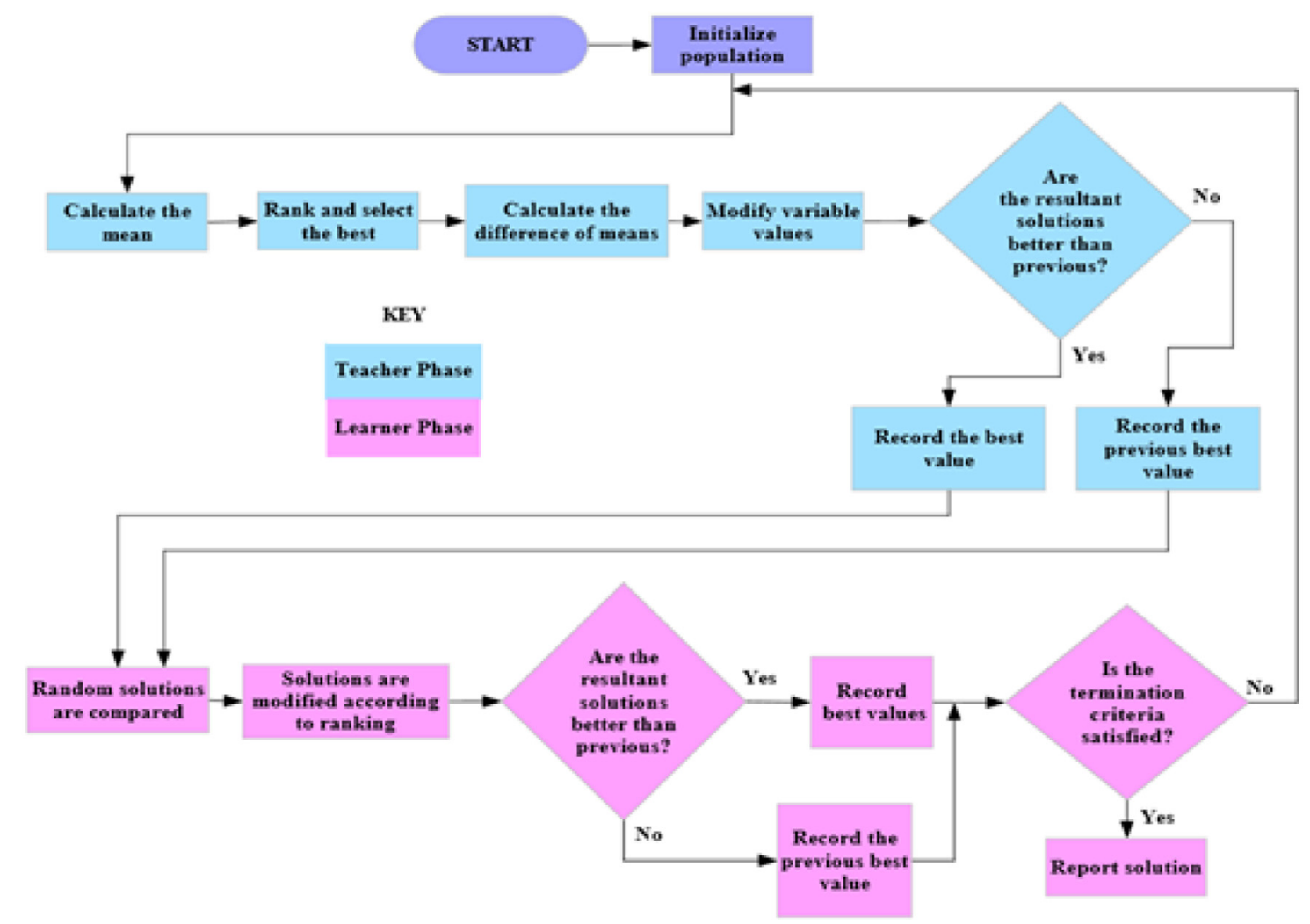

Fig. 4. TLBO flow chart [3].

section of the algorithm. In this phase, ideally, the class session has ended and students have begun interacting on their own without the teacher. Such interaction results in the appreciation of the lower level learner. However, the acquired level of knowledge does not degrade by interacting with a lower level learner. Considering a population of size ' $n$ ', the learning phenomenon begins with a random selection of any two learners as shown in Figure 3. These two values may not be equal and update in a similar way as in the teacher phase but according to formulations [21] dependent on which value is greater. The formulations also differ according to the nature of the objective for either maximization or minimization. This process iterates subject to the termination criterion otherwise, the algorithm loops back to the learner stage.

- Maximum iterations $=50$

- Teaching factor $=1$

\subsection{Firefly algorithm}

The FA technique synthesizes the light emmiting characters of fire flies for metaheuristic optimization purposes. It can be classified under swarm intelligence based methods [23]. The firefly algorithm (FA) was developed by Yang [23].

A member in the search space here referenced as the firefly has an attractiveness rating proportional of the brightness of luminesce. Naturally light varies with distance and has an absorption limit, therefore in order to estimate or approximate the extent of luminesce a nonlinear expression is applied. Therefore, mathematically the position $\mathrm{x}$ is defined as;

$$
x_{i}^{(t+1)}=x_{i}^{t}+\beta_{0} e^{\left(-\gamma r_{(i j)}^{2}\right)}\left(x_{j}^{t}-x_{i}^{t}\right)+\alpha \in_{i}^{t} .
$$

Here $\alpha$ represents the scaling factor, which regulates strides in the walks. The visual appearance is regulated by the scale-dependent parameter, $\gamma . \beta_{0}$, is the attraction constant at zero distance.

In summary the following four guiding principles are applied in its execution:

- Non-selective attraction amongst members

- Higher brightness members are more attractive.

- Random movement will occur where brightness gradient is low.

- Brightness is analogous to fitness function

Various options used in this algorithm

- Maximum number of Iterations $=50$

- Swarm size (population) $=25$;

- Light absorption coefficient gamma $=1$;

- Attraction Coefficient beta $=2$;

- Mutation Coefficient alpha $=0.2$;

- Mutation Coefficient Damping Ratio $=0.98$;

FA is implemented as shown in Figure 5. Initialization and objective function evaluation is followed by ranking of fireflies using brightness. The brightest is the best function 


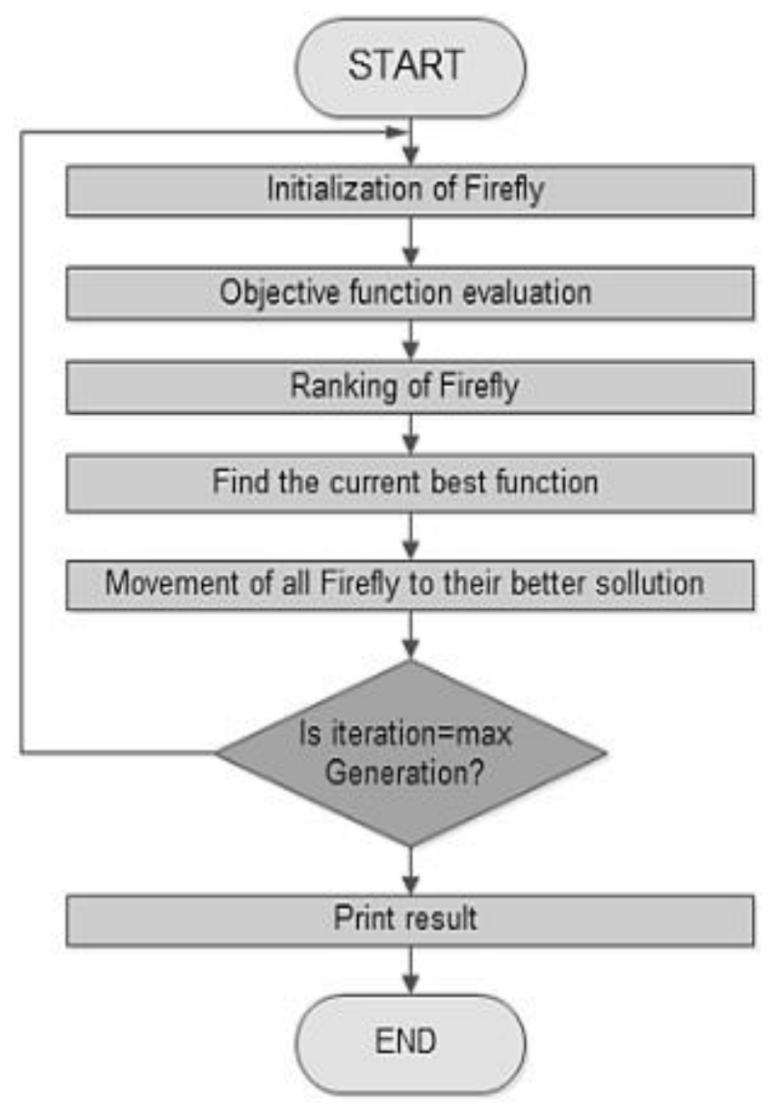

Fig. 5. Firefly algorithm [22].

which will be attractive hence a better solution is achieved and this process continues until maximum number of iterations is reached.

\subsection{Particle Swarm Optimization (PSO)}

PSO is a metaheuristic method that is based on the social activity of birds or fish as they search for food [24]. Furthermore, either group is assumed to be in search for a specific food unit/item. The specific location of this item is not apparent to each bird or fish. However, the number of steps to the food item is clear. Unlike other algorithms, there is no elimination of initial population but rather a gradual improvement in solution [16]. Each particle in the PSO algorithm is defined by two characters position and velocity.

The former is the fitness value while the latter regulates movement of the particle. In summary, the PSO algorithm is executed in Figure 6.

- Random initialization of the population composed of particles with attributes position and velocity over a search space.

- Evaluate the position attribute, which defines the fitness function.

- For subsequent solutions the current particle best value is compared with the previous value and the superior value becomes the new particle best value.

- Considering a district of particles, a variable $g$ is referenced to the best particle value.

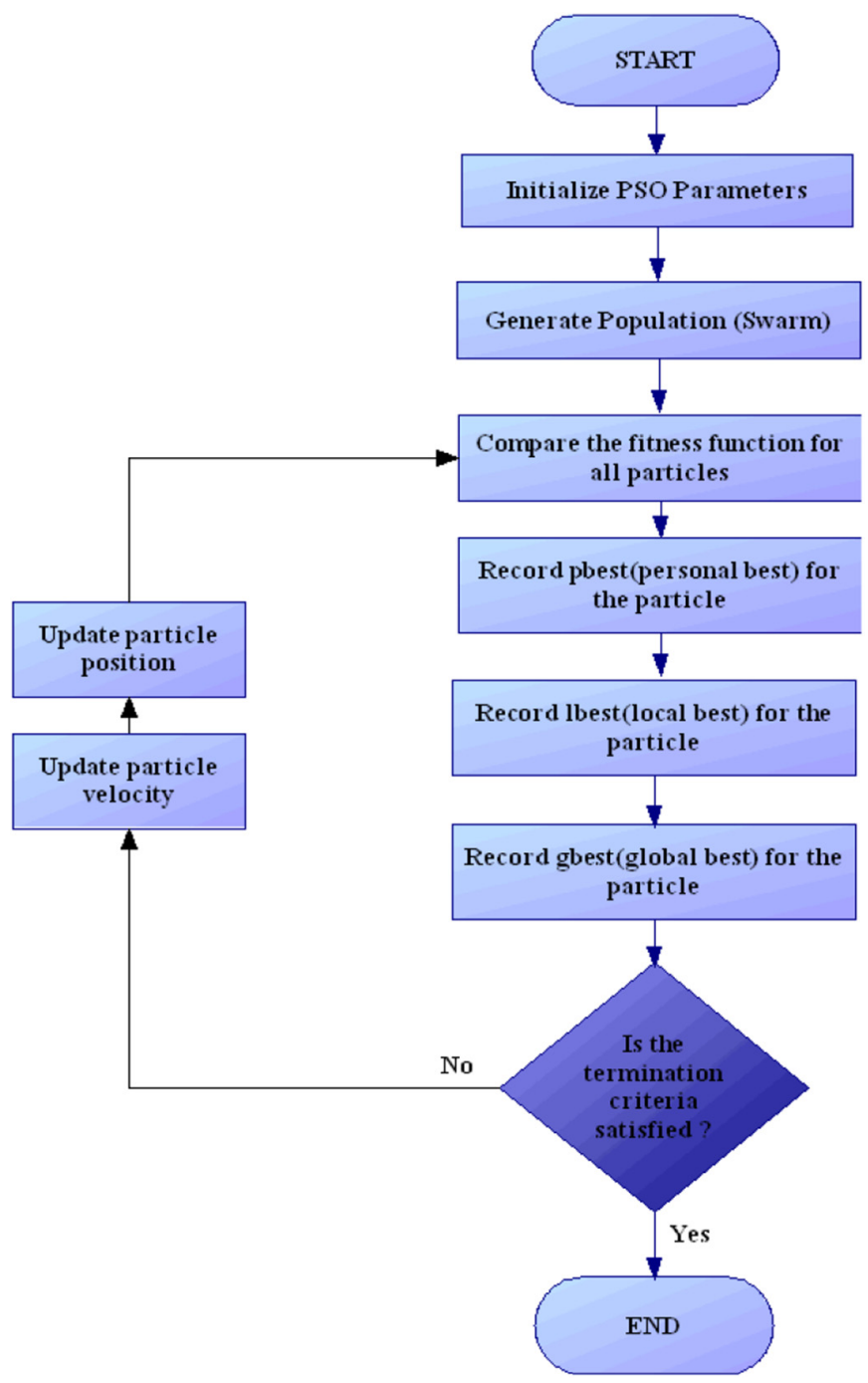

Fig. 6. PSO flow chart.

- An update of particle attributes, using equations (3) and (4) respectively

$v_{i d}=v_{i d}+c_{1 *} \operatorname{rand}()^{*}\left(p_{i d}-x_{i d}\right)+c_{2}^{*} \operatorname{Rand}()^{*}\left(p_{i d}-p_{g d}\right)$

$$
x_{i d}=x_{i d}+v_{i d}
$$

- If criterion or maximum number of iterations is satisfied then return to step 2 .

The following PSO parameters have been applied in this study,

- Maximum iterations $=50$

- Inertia weight $(\mathrm{w})=1$

- Inertia Weight Damping Ratio (iwd) $=0.97 \quad$ (using random weight formula) [25]

- Personal learning coefficient $\left(c_{1}\right)=1.6$

- Global learning coefficient $\left(c_{2}\right)=1.9$

- Maximum velocity $=0.1 \times($ Variable Range $)$

- Minimum velocity $=-($ Maximum velocity $)$ 


\section{Problem description}

Minimize

$$
V o l=\left[b, m, z_{1}, d_{1}, d_{2}, H\right]
$$

Design variables

$$
\begin{gathered}
20 \leq b \leq 40 \\
3 \leq m \leq 10 \\
17 \leq z_{1} \leq 60 \\
25 \leq d_{1} \leq 35 \\
40 \leq d_{2} \leq 60 \\
200 \leq H \leq 400
\end{gathered}
$$

Subject to

$$
\begin{gathered}
g_{1}=\sigma_{b}-\frac{\sigma_{b(\text { all })} Y_{N}}{S_{F} Y_{\vartheta} Y_{Z}} \leq 0 \\
g_{2}=\sigma_{C}-\frac{\sigma_{c(\text { all })} Z_{N} C_{H}}{S_{H} K_{T} K_{R}} \leq 0
\end{gathered}
$$

Where $V o l$ is defined by volume of solid profile, $V_{\text {solid }}$, shown in equation (14), volume of hole profile $V_{\text {holes, }}$, equation (15), volume for hole-hub profile $V_{\text {hole-hub }}$ shown in equation (16), and volume for hub profiles, $V_{\text {hubs }}$ shown in equation (17).

$$
\begin{gathered}
V_{\text {solid }}=\sum_{x=1}^{x=n}\left[\left[\frac{\pi}{4} \times D_{x}^{2} \times b\right]-\left[\frac{\pi}{4} \times D_{x}^{2} \times b\right]\right] \\
V_{\text {holes }}=\sum_{x=1}^{x=n}\left[\left[\frac{\pi}{4} \times D_{x}^{2} \times b\right]-\left[\frac{\pi}{4} \times d_{x}^{2} \times b\right]-\right] \\
V_{\text {holeshubs }}=\sum_{x=1}^{x=n}\left(V_{\text {solid }}^{2} \times b\right] \times\left(n_{w}\right) \\
-\sum_{x=1}^{x=n}\left[\left[\left(\frac{\pi}{4} \times\left(d_{h 1}-d_{h 2}\right)^{2} \times b\right) \times\left(2 b_{w}\right)\right]\right. \\
V_{\text {hubs }}=\sum_{x=1}^{x=n}\left(V_{\text {solid }}\right) \\
-\sum_{x=1}^{x=n}\left[\left[\left(\frac{\pi}{4} \times\left(d_{w x}^{2} \times b\right] \times\left(n_{w}\right)\right.\right.\right.
\end{gathered}
$$

The constraints of the system are represented by equations (12) and equation (13) which are interpreted

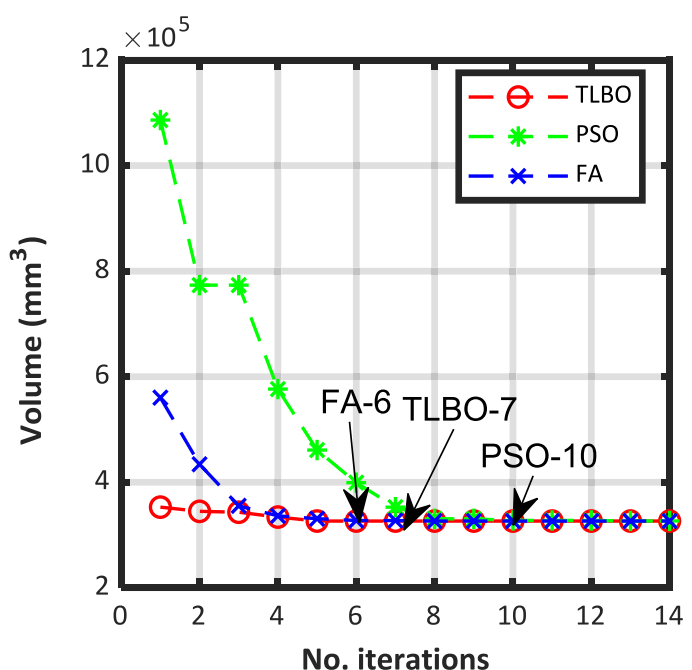

Fig. 7. Hub profile convergence results.

according to ISO 6336-1 to ISO 6336-3. The summary of terms in equations (12) and (13) are defined in equations (18) to (21).

$$
\begin{gathered}
\sigma_{b}=W^{t} K_{o} K_{v} K_{s} \frac{1}{b_{m t}} \frac{K_{m} K_{B}}{Y_{j}} \\
\sigma_{b(\text { all })}=2.41 H+237 \\
\sigma_{C}=C_{p} \sqrt{W^{t} K_{o} K_{v} K_{s} \frac{K_{m}}{d F} \frac{C_{f}}{I}} \\
\sigma_{c(\text { all })}=0.703 H+237
\end{gathered}
$$

where, $W^{t}$, tangential load, bw, Hub recess (mm), dw-hole diameter $(\mathrm{mm}),-$ number of holes, rim thickness $K_{B}$, overload $K_{o}$, dynamic $K_{v}$, size $K_{s}$, load distribution $K_{m}$, temperature $K_{T}$, reliability $K_{R}$, contact stress factor $C_{H}$, geometry factor of bending stress $J$, stress cycle factor for contact stress $Z_{N}$, stress cycle factor for bending strength $Y_{N}$, surface condition factor $C_{f}$, elasticity coefficient $C_{p}$.

\section{Results and discussions}

In the present study, three algorithms viz. TLBO, PSO and FA where applied to study parameter influence in volume minimization of spur gears. A single stage spur gear model was investigated utilizing four different structures. Six variables viz. module, face-width, pinion tooth number, gear shaft diameters and hardness were employed. Each algorithm was set for fifty (50) iterations and the results are shown in this section of the research work.

Considering the hub profile, in Figure 7, FA converged after six (6) iterations, while TLBO and PSO converged after seven (7) and ten (10) iterations respectively. In the hub-hole profile, shown in Figure 8 the convergence for FA, 


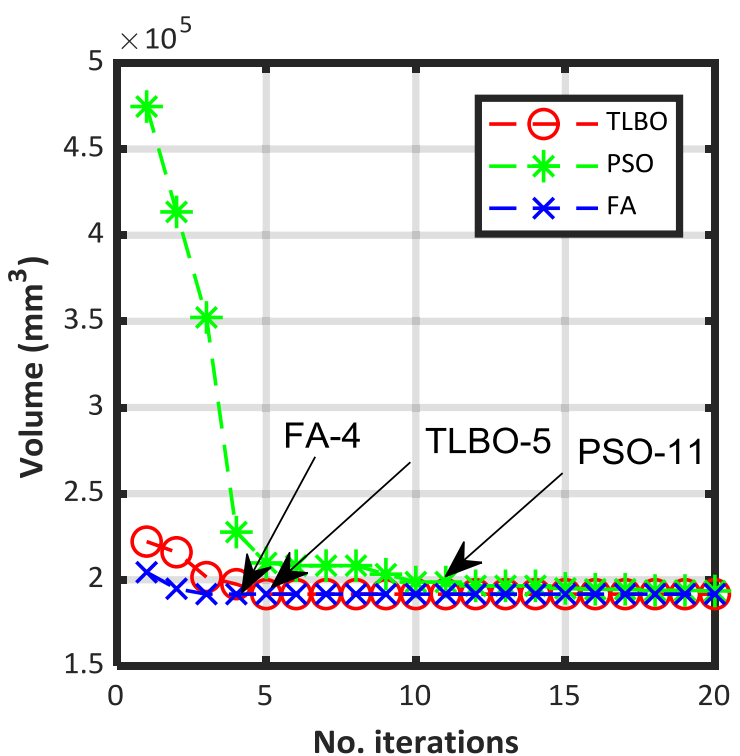

Fig. 8. Hub-hole profile convergence results.

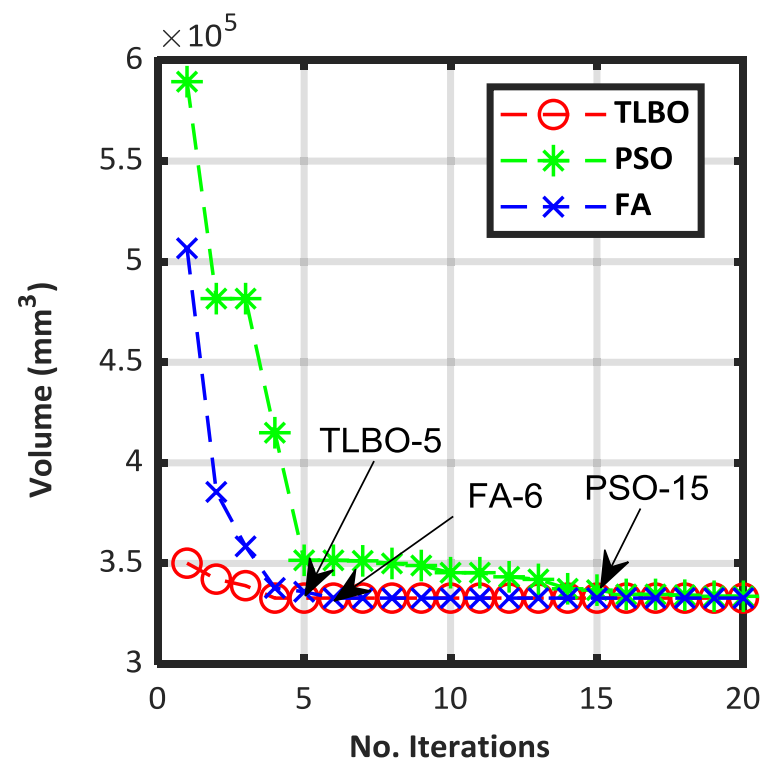

Fig. 9. Solid profile convergence results.

TLBO and PSO is shown as four (4), five (5) and eleven (11) respectively. For the solid profile convergence was achieved at 5,6 and 15 iterations for TLBO, FA and PSO algorithms (Fig. 9). However, for the hole profile, in Figure 10, both FA and TLBO converged at six (6) iterations while PSO converged at twenty-five (25) iterations. In an overall assessment, FA had a faster convergence rate in most cases except for the solid profile where TLBO converged earlier. In the case of hole-profile, FA and TLBO converged at the same rate. The rate of convergence could be attributed to algorithm simplicity. The TLBO algorithm is a parameterless algorithm while FA has fewer parameters than PSO.

The optimal results for the four gear structures investigated in this study are shown in Table 2. Generally,

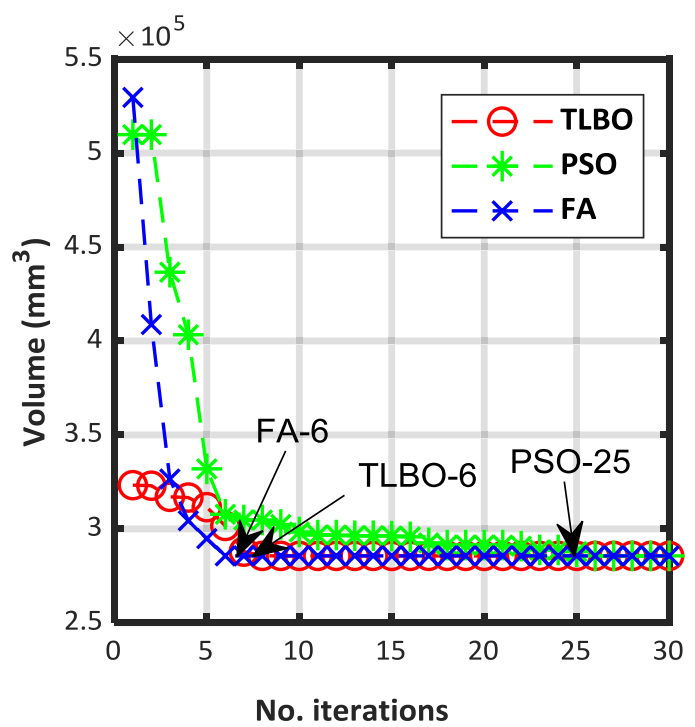

Fig. 10. Hole-profile convergence results.

optimal results were similar in all cases except for solid, hole and hub-hole profiles under the PSO technique. The optimal volume was higher at 333789.3, 289132 and $193717.1 \mathrm{~mm}^{3}$ compared to other algorithm results reflecting variances of $0.3 \%, 0.16 \%$ and $1 \%$ respectively.

Greater variance was observed in the hardness factor where the solid profile has a lower hardness factor as compared to the reported results shown in Table 2. In order to analyse performance of the algorithms applied, experimental studies were done for each algorithm and computed for mean, optimal and standard deviation values. Table 3 reports results for hub-profile and solid profile while Table 4 shows results for hole and hub-hole profiles. As shown in Table 3 , for the hub and solid profile, PSO obtained the highest deviation of 26225.2 followed by TLBO at 5836.9 and 7314.9 , while FA has the least at 0 and 1160.8. Considering the hole and hub-hole profiles, FA had the highest deviations at 4684.4 and 4192.0 while TLBO obtained 0.221 and 1.52 respectively.

\section{Variation study}

Module and volume variation studies are shown in Figure 11. Facewidth variation at gear ratio 3 and 2 have the greatest influence on module and volume. In this case for lower module values volume change is relatively minor for every change in module. However, for higher module values even small changes in module have potential for higher volume change. The degree of influence in descending order is as follows viz. facewidth, pinion teeth number and shaft diameters. Interestingly, below module size 8 , variation is similar for facewidth at gear ratio 2 and pinion tooth number at gear ratio 3 . The same analogy applies for pinion tooth number at gear ratio 2 and pinion shaft diameter at gear ratio 3 for module size less than 11. 
Table 2. Optimal results.

\begin{tabular}{|c|c|c|c|c|c|c|c|c|c|}
\hline Algorithm & Gear structure & $\begin{array}{l}\text { Volume } \\
\left(\mathrm{mm}^{3}\right)\end{array}$ & $m$ & $\begin{array}{l}B \\
(\mathrm{~mm})\end{array}$ & $\mathrm{z} 1$ & $\begin{array}{l}\mathrm{d} 1 \\
(\mathrm{~mm})\end{array}$ & $\begin{array}{l}\mathrm{d} 2 \\
(\mathrm{~mm})\end{array}$ & $H$ & $\begin{array}{l}\text { No. } \\
\text { iterations }\end{array}$ \\
\hline \multirow{3}{*}{ TLBO } & Hub-profile & 326510.6 & 3 & 20 & 17 & 35 & 60 & 340 & 7 \\
\hline & Hole-profile & 285649.3 & 3 & 20 & 17 & 35 & 60 & 370 & 5 \\
\hline & Hub-hole profile & 191676.4 & 3 & 20 & 17 & 35 & 60 & 400 & 6 \\
\hline \multirow{2}{*}{ PSO } & Hole-profile & 286132 & 3 & 20 & 17 & 34 & 60 & 339 & 15 \\
\hline & Hub-hole profile & 193767.1 & 3 & 20 & 17 & 33 & 60 & 382 & 25 \\
\hline \multirow{2}{*}{ FA } & Hub-profile & 326510.6 & 3 & 20 & 17 & 35 & 60 & 376 & 6 \\
\hline & Solid profile & 332773.2 & 3 & 20 & 17 & 35 & 60 & 322 & 4 \\
\hline
\end{tabular}

Table 3. Volume $\left(\mathrm{mm}^{3}\right)$ experimentation results for hub-profile and solid-profile.

\begin{tabular}{|c|c|c|c|c|c|c|}
\hline \multirow[t]{2}{*}{ Experiment No. } & \multicolumn{3}{|c|}{ Hub profile } & \multicolumn{3}{|c|}{ Solid profile } \\
\hline & TLBO & $\mathrm{PSO}$ & FA & TLBO & PSO & FA \\
\hline 1 & 326510.6 & 326511.6 & 326510.6 & 332773.2 & 334937.8 & 332773.2 \\
\hline 2 & 326510.6 & 326510.6 & 326510.6 & 332773.2 & 416270 & 336480 \\
\hline 3 & 331513.6 & 326649.6 & 326510.6 & 339531.8 & 354500 & 332773.2 \\
\hline 4 & 344842.2 & 327896.6 & 326510.6 & 350231.2 & 332773.2 & 332773.2 \\
\hline 5 & 326510.6 & 328808 & 326510.6 & 332773.2 & 332773.2 & 332773.2 \\
\hline 6 & 326510.6 & 328090 & 326510.6 & 332773.2 & 332870.1 & 332773.2 \\
\hline 7 & 326510.6 & 326510.6 & 326510.6 & 332773.2 & 333665.2 & 332980 \\
\hline 8 & 326510.6 & 330444.1 & 326510.6 & 332773.2 & 333396.5 & 332980 \\
\hline 9 & 326510.6 & 326510.6 & 326510.6 & 332773.2 & 335264.7 & 332773.2 \\
\hline 10 & 326510.6 & 327939 & 326510.6 & 350231.2 & 333848.9 & 332773.2 \\
\hline Standard deviation & 5836.9 & 1318.2 & 0 & 7314.9 & 26225.2 & 1160.8 \\
\hline Mean & 328844 & 327587.1 & 326510.59 & 336940.7 & 344029.96 & 333185.2 \\
\hline Optimal & 326510.59 & 326510.59 & 326510.59 & 332773.2 & 332773.2 & 332773.2 \\
\hline
\end{tabular}

Volume and facewidth variation study is shown in Figure 12 and module has the greater influence over pinion tooth number and pinion shaft diameter respectively.

Pinion shaft diameter at gear ratio 3 and pinion tooth number at gear ratio 2 have identical influence in the volume facewidth variotion study done. Pinion shaft diameter was also varied against volume as shown in Figure 13. In this case, module exhibited the greatest influence over pinion tooth number and facewidth respectivey. At lower shaft diameter values facewidth at gear ratio 3 had greater influence as compared to module at gear ratio 2 . Pinion tooth number at gear ratio 3 was similar face width variation at gear ratio 2 .

Pinion tooth number is another important parameter that was studied, hence Figure 14 shows the plot of variances. Module showed the highest influence over facewidth and pinion tooth numbers.
These variations reflect the practical nature of gear design. Generally gears with large modules tend to have higher facewidth values which accounts for the exponential rise in the volume realised. Module is direclty related to the diameter of the gear and facewidth values affect the thickness of the gear. Increase in these two parameters results in volume increase.

\section{Conclusion}

A single stage spur gear design problem has been formulated across four volume models and optimized for minimum volume using three optimization methods viz. Teaching learning-based optimization, Firefly algorithm and Particle swarm optimization. Analysis of results reflects on the interdependence and sensitivities against the minimum volume objective. PSO obtained the highest 
Table 4. Volume $\left(\mathrm{mm}^{3}\right)$ experimentation results for hole-profile and hub-hole-profile.

\begin{tabular}{llllllll}
\hline Experiment No. & \multicolumn{3}{c}{ Hole profile } & & \multicolumn{3}{c}{ Hub-hole profile } \\
\cline { 2 - 3 } & TLBO & PSO & FA & & TLBO & PSO & FA \\
\hline $\mathbf{1}$ & 285650 & 288718.9 & 286310 & & 191676.4 & 191719.7 & 191676.4 \\
$\mathbf{2}$ & 285649.3 & 285650 & 292250 & & 191680 & 192033.4 & 191676.4 \\
$\mathbf{3}$ & 285649.3 & 287339.3 & 285649.3 & & 191676.4 & 191676.4 & 192410 \\
$\mathbf{4}$ & 285649.3 & 285649.3 & 285649.3 & & 191680 & 191676.4 & 201350 \\
$\mathbf{5}$ & 285649.3 & 291475.2 & 285649.3 & & 191680 & 196518.4 & 201790 \\
$\mathbf{6}$ & 285649.3 & 285649.3 & 285649.3 & & 191680 & 191676.4 & 191680 \\
$\mathbf{7}$ & 285649.3 & 285649.3 & 294430 & & 191680 & 196885.4 & 197000 \\
$\mathbf{8}$ & 285649.3 & 285667.4 & 289230 & & 191680 & 191650.3 & 198930 \\
$\mathbf{9}$ & 285649.3 & 287008.9 & 298700 & & 191680 & 192458.5 & 191676.4 \\
$\mathbf{1 0}$ & 285649.3 & 287576.5 & 285649.3 & & 191680 & 193021.2 & 193670 \\
Standard deviation & $\mathbf{0 . 2 2 1}$ & $\mathbf{1 8 9 9 . 9}$ & $\mathbf{4 6 8 4 . 4}$ & & $\mathbf{1 . 5 2}$ & $\mathbf{2 0 3 7 . 8}$ & $\mathbf{4 1 9 2 . 1}$ \\
Mean & $\mathbf{2 8 5 6 4 9 . 3}$ & $\mathbf{2 8 7 0 3 8 . 4}$ & $\mathbf{2 8 8 9 1 6 . 6}$ & $\mathbf{1 9 1 6 7 9 . 3}$ & $\mathbf{1 9 2 9 3 1 . 6}$ & $\mathbf{1 9 5 1 8 5 . 9}$ \\
Optimal & $\mathbf{2 8 5 6 4 9 . 3}$ & $\mathbf{2 8 5 6 4 9 . 3}$ & $\mathbf{2 8 5 6 4 9 . 3}$ & $\mathbf{1 9 1 6 7 6 . 4}$ & $\mathbf{1 9 1 6 5 0 . 3}$ & $\mathbf{1 9 1 6 7 6 . 4}$ \\
\hline
\end{tabular}

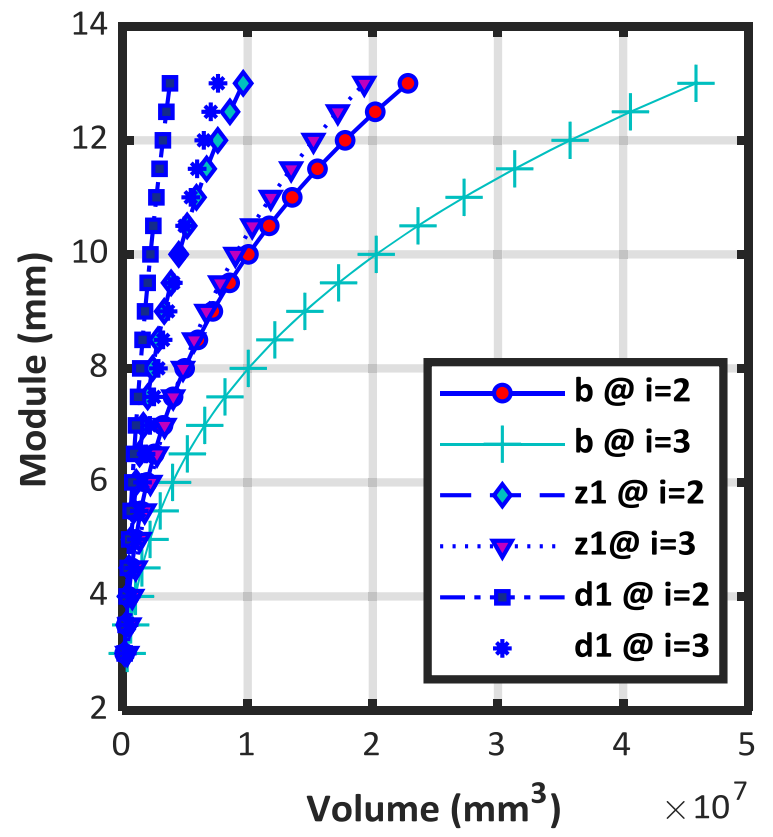

Fig. 11. Volume/module variation.

deviation of 26225.2 and had a slower convergence speed followed by TLBO at 5836.9 and 7314.9 , while FA has the least at 0 and 1160.8 which converged at a faster rate. Considering the hole and hub-hole profiles, FA had the highest deviations at 4684.4 and 4192.0 while TLBO obtained 0.221 and 1.52 respectively with fast convergence rates. On the other hand PSO had a median deviation but slow convergence rates.

The following conclusions give the sum of observations: - TLBO and FA algorithms have faster convergence rates.

- In the given study, there is higher volume reduction from holes as compared to gear hubs, which could be as a

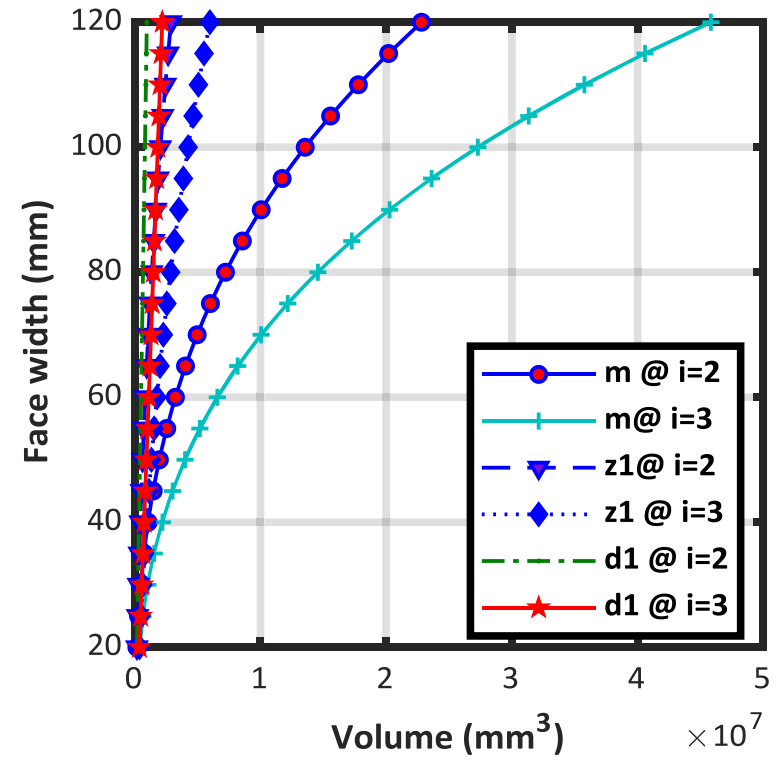

Fig. 12. Volume/face-width variation.

result of holes cut through the entire width of the gear blank.

- Not all variables have a similar contribution to the volume objective with module variation accounting for at least $50 \%$ in volume increase compared to other variables in all scenarios presented.

- The teeth number and module of gear have more influence in the volume variable as compared to the facewidth and internal diameter of gear. This observation reflects that there is, practically, more variance in volume of a gear cross-section wise, than axially.

- Gear ratio selection is an important step as variables such as face width exhibited more influence at higher pinion tooth numbers. 


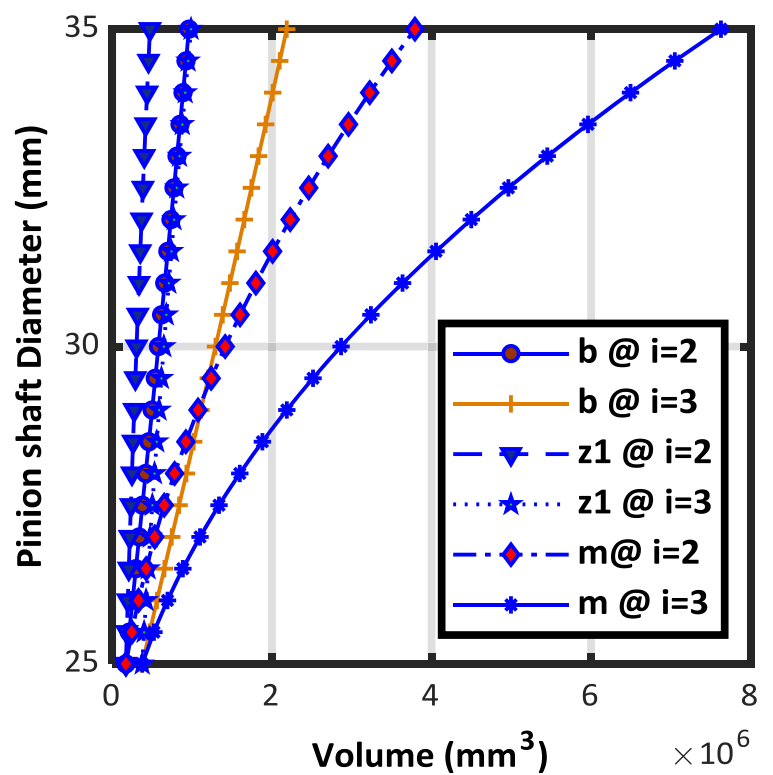

Fig. 13. Volume/pinion shaft diameter variation.

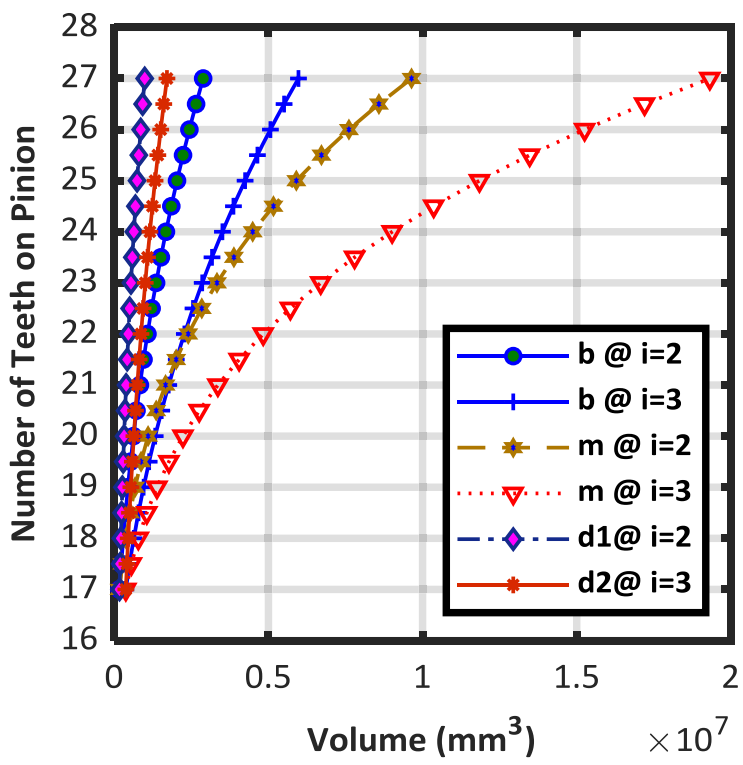

Fig. 14. Volume/ pinion tooth number variation.

- The selection of module and the teeth number for a gear or pinion is an important step in the minimization of gear weight.

Future research work will focus on further defining the influence of variables on more than one objective.

\section{Nomenclature}

$\begin{array}{ll}b & \text { Face width }(\mathrm{mm}) \\ m & \text { Module } \\ d_{1} & \text { Pinion shaft diameter } \\ d_{2} & \text { Gear shaft diameter }\end{array}$

D $\quad$ Gear diameter

$H \quad$ Material hardness number

$\alpha \quad$ Scaling factor (FA).

$\gamma \quad$ Scale-dependent parameter(FA)

$\beta_{0} \quad$ Is the attraction constant at zero distance (FA)

$P_{\text {in }} \quad$ Power input $(\mathrm{kW})$

$\mathrm{CD} \quad$ centre distance $(\mathrm{mm})$

$z_{1}, z_{2} \quad$ Number of teeth on pinion, gear

$w \quad$ Inertia weight

iwd Inertia weight damping ratio

$c_{1} \quad$ Personal learning coefficient

$c_{2} \quad$ Global learning coefficient

Vol Volume

$V_{\text {solid }} \quad$ Volume of solid profile

$V_{\text {holes }} \quad$ Volume of hole profile

$V_{\text {hole-hub }}$ Volume for hole-hub profile

$V_{\text {hubs }} \quad$ Volume for hub profiles

$J \quad$ Geometry factor of bending stress

$W^{t} \quad$ Tangential load

bw Hub recess (mm)

$\mathrm{dw} \quad$ Hole diameter $(\mathrm{mm})$

$d_{p} \quad$ Number of holes

$K_{B} \quad$ Rim thickness

$K_{o} \quad$ Overload

$K_{v} \quad$ Dynamic

$K_{s} \quad$ Size

$K_{m} \quad$ Load distribution

$K_{T} \quad$ Temperature

$K_{R} \quad$ Reliability

$C_{H} \quad$ Contact stress factor

$Z_{N} \quad$ Stress cycle factor for contact stress

$Y_{N} \quad$ Stress cycle factor for bending strength

$C_{f} \quad$ Surface condition factor

$C_{p} \quad$ Elasticity coefficient

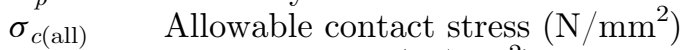

$\sigma_{b} \quad$ Bending stress $\left(\mathrm{N} / \mathrm{mm}^{2}\right)$

$\sigma_{b(\text { all })} \quad$ Allowable bending stress $\left(\mathrm{N} / \mathrm{mm}^{2}\right)$

$\theta \quad$ Pressure angle

$\sigma_{c} \quad$ Contact stress $\left(\mathrm{N} / \mathrm{mm}^{2}\right)$

\section{References}

1. T. Yokota, T. Taguchi, M. Gen, A solution method for optimal weight design problem of the gear using genetic algorithms, Comput. Ind. Eng. 35, 523-526 (1998)

2. V. Savsani, R.V. Rao, D.P. Vakharia, Optimal weight design of a gear train using particle swarm optimization and simulated annealing algorithms, Mech. Mach. Theory 45, 531-541 (2010)

3. E.S. Maputi, R. Arora, Design optimization of a three-stage transmission using advanced optimization techniques, Int. J. Simul. Multidiscip. Des. Optim. 10, A8 (2019)

4. A. Zolfaghari, M. Goharimanesh, A.A. Akbari, Optimum design of straight bevel gears pair using evolutionary algorithms, J. Br. Soc. Mech. Sci. Eng. 39, 2121-2129 (2017)

5. Y.K. Mogal, V.D. Wakchaure, A multi-objective optimization approach for design of worm and worm wheel based on genetic algorithm, Bonfring Int. J. Man Mach. Interface 1, 08 (2013) 
6. K. Tamboli, S. Patel, P.M. George, R. Sanghvi, Optimal design of a heavy-duty helical gear pair using particle swarm optimization technique, in Proc. Second International Conference on Innovations in Automation and Mechatronics Engineering, ICIAME 2014, Vallabh Vidyanagar, India, 2014, pp. 513-519

7. P. Rai et al., Volume optimization of helical gear with profile shift using real coded genetic algorithm, Proc. Comput. Sci. 133, 718-724 (2018)

8. E.S. Maputi, R. Arora, Multi-objective spur gear design using teaching learning-based optimization and decision-making techniques, Cogent Eng. 6, 1 (2019)

9. L. Kaiyue, C. Guoding, L. Deng, Study of the influence of lubrication parameters on gear lubrication properties, Ind. Lubric. Tribol. 68, 647-657 (2016)

10. S. Baglioni, F. Cianetti, L. Landi, Influence of the addendum modification on spur gear efficiency, Mech. Mach. Theory 49, 216-233 (2012)

11. F.I. Petrescu, R.V. Petrescu, High efficiency gears, Facta Univ. Ser. Mech. Eng. 12, 51-60 (2014)

12. C. Wang, S. Wang, G. Wang, Volume models for different structures of spur gear, Aust. J. Mech. Eng. (2017), DOI: 10.1080/14484846.2017.1381373

13. S. Golabi, J.J. Fesharaki, M. Yazdipoor, Gear train optimization based on minimum volume/weight design, Mech. Mach. Theory 73, 197-217 (2014)

14. BS-ISO 6336-3:2006, 'Calculation of load capacity of spur and helical gears - Part 3: Calculation of tooth bending strength', p. 5

15. M. Dörterler, İ. Sahin, H. Gökçe, A grey wolf optimizer approach for optimal weight design problem of the spur gear (2018) DOI: 10.1080/0305215X.2018.1509963

16. A. Messac, Optimization in Practice with MATLAB: For Engineering Students and Professionals (Cambridge University Press, 2015), 147p

17. D. Das, S. Bhattacharya, B. Sarkar, Decision-based designdriven material selection: a normative-prescriptive approach for simultaneous selection of material and geometric variables in gear design, Mater. Des. 92, 787-793 (2016)

18. J. Arora, Introduction to Optimum Design, Third Edition (2011)

19. K. Deb, S. Jain, Multi-speed gearbox design using multiobjective evolutionary algorithms, J. Mech. Des. 125, 609 (2003)

20. C. Gologlu, M. Zeyveli, A genetic approach to automate preliminary design of gear drives, Comput. Ind. Eng. 57, 1043-1051 (2009)

21. R. Venkata, Review of applications of TLBO algorithm and a tutorial for beginners to solve the unconstrained and constrained optimization problems, Decis. Sci. Lett. 1-30 (2016)

22. R. Kumar et al., Quality factor optimization of spiral inductor using firefly algorithm and its application in amplifier, Int. J. Adv. Intell. Parad. 11 (2018) DOI: 10.1504/IJAIP.2018.10016456

23. I. Arora, A. Saha, Software fault prediction using firefly algorithm, Int. J. Intell. Eng. Inf. 6, 356 (2018)

24. M.A. Khodja, M. Tadjine, M.S. Boucherit, M. Benzaoui, Tuning PID attitude stabilization of a quadrotor using particle swarm optimization (experimental). Int. J. Simul. Multisci. Des. Optim. 8, A8 (2017)

25. J.C. Bansal et al., Inertia weight strategies in Particle swarm optimization. Third World Congress on Nature and Biologically Inspired Computing IEEE 2011. DOI: 10.1109/ NaBIC.2011.6089659

26. R. Arora, S.C. Kaushik, R. Kumar, R. Arora, Multi-objective thermo-economic optimization of solar parabolic dish Stirling heat engine with regenerative losses using NSGA-II and decision making, Int. J. Electr. Power Energy Syst. 74, 25-35 (2016)

27. R. Arora, S.C. Kaushik, R. Arora, Multi-objective and multiparameter optimization of two-stage thermoelectric generator in electrically series and parallel configurations through NSGA-II, Energy 91, 242-254 (2015)

28. R. Arora, S.C. Kaushik, R. Arora, Thermodynamic modeling and multi-objective optimization of two stage thermoelectric generator in electrically series and parallel configuration, Appl. Therm. Eng. 103, 1312-1223 (2016)

29. R. Kumar, S.C. Kaushik, R. Kumar, R. Hans, Multi-objective thermodynamic optimization of an irreversible regenerative Brayton cycle using evolutionary algorithm and decision making, Ain Shams Eng. J. 7, 741-753 (2016)

30. R. Arora, S.C. Kaushik, R. Kumar, R. Arora, Soft computing based multi-objective optimization of Brayton cycle power plant with isothermal heat addition using evolutionary algorithm and decision making, Appl. Soft Comput. 46, 267-283 (2016)

31. R. Arora, S.C. Kaushik, R. Kumar, Multi-objective thermodynamic optimisation of solar parabolic dish Stirling heat engine using NSGA-II and decision making, Int. J. Renew. Energy Technol. 8, 64-92 (2017)

32. R. Arora, S.C. Kaushik, R. Kumar, Multi-objective thermodynamic optimization of solar parabolic dish Stirling heat engine with regenerative losses using NSGA-II and decision making, Appl. Solar Energy 52, 295-304 (2016)

33. R. Arora, R. Arora, Multiobjective optimization and analytical comparison of single-and 2-stage (series/parallel) thermoelectric heat pumps, Int. J. Energy Res. 42, 1760-1778 (2018)

34. R. Arora, R. Arora, Multicriteria optimization based comprehensive comparative analyses of single-and two-stage (series/ parallel) thermoelectric generators including the influence of Thomson effect. J. Renew. Sustain. Energy 10, 044701 (2018)

35. S. Ahmed, R. Arora, Optimization of turning parameters of Aluminum 6351 T6 using Taguchi decision making technique, Int. J. Data Netw. Sci. 1, 27-38 (2017)

Cite this article as: Edmund S. Maputi, Rajesh Arora, Influence of geometric variables on spur gear volume, Int. J. Simul. Multidisci. Des. Optim. 11, 8 (2020) 